\title{
Atividades séricas da aspartato aminotransferase, creatina quinase e lactato desidrogenase de eqüinos submetidos ao teste padrão de exercício progressivo em esteira
}

Armen THOMASSIAN ${ }^{1}$

Fernanda de CARVALHO

Marcos Jun WATANABE ${ }^{1}$

Veridiana Fernandes da

SILVEIRA ${ }^{3}$

Ana Liz Garcia ALVES ${ }^{1}$

Carlos Alberto HUSSNI ${ }^{1}$

José Luiz de Mello

NICOLETTI ${ }^{1}$

${ }^{1}$ Correspondência para:

Prof. Dr. Armen Thomassian

Departamento deCirurgia e Anestesiologia

Veterinária Faculdade de Medicina

Veterinária e Zootecnia-UNESP-Botucatu

Distrito de Rubião Júnior CP. 560;

CEP: 18618000 - Botucatu - São Paulo

E-mail: thomassian@fmvz.unesp.br

Recebido para publicação: 23/06/2005 Aprovado para publicação: 05/04/2007

\author{
1- Departamento de Cirurgia e Anestesiologia Veterinária, Faculdade de Medicina \\ Veterinária e Zootecnia, Universidade Estadual Paulista, Botucatu-SP \\ 2 - Aluna de Iniciação Científica, Faculdade de Medicina Veterinária e Zootecnia, \\ Universidade Estadual Paulista, Botucatu - SP \\ 3 - Departamento de Clínica Veterinária, Faculdade de Medicina Veterinária e \\ Zootecnia, Universidade Estadual Paulista, Botucatu - SP
}

RESUMO

Objetivou-se determinar a atividade sérica das enzimas aspartato aminotransferase (AST), creatina quinase (CK) e lactato desidrogenase (LDH) de cavalos da raça Árabe submetidos a exercício em esteira de alta velocidade. Onze eqüinos adultos da raça Árabe foram condicionados e submetidos ao Teste Padrão de Exercício Progressivo em esteira. Antes, imediatamente após o término do exercício, e nos momentos pós-exercício, 30min, 60min, 3h, 6h, 12h, 24h, 3 dias e 5 dias, foram coletadas amostras de sangue venoso para as determinações séricas das enzimas aspartato aminotransferase (AST), creatina quinase (CK) e lactato desidrogenase $(\mathrm{LDH})$. As concentrações séricas da AST, da CK e da LDH elevam-se imediatamente e retornam a valores semelhantes ao de repouso 30 minutos após o término do Teste Padrão de Exercício Progressivo. A atividade enzimática da aspartato aminotransferase (AST) eleva-se de 12 horas a 24 horas, da creatina quinase $(\mathrm{CK})$ de 3 horas a 6 horas e da lactato desidrogenase (LDH) 24 horas após o término do Teste Padrão de Exercício Progressivo.

\section{Introdução}

A refinada coordenação neuromuscular, a força e a resistência musculares, fazem com que cavalos atletas consigam atingir a velocidade de até $65 \mathrm{~km} / \mathrm{h}$. Essa capacidade é decorrente da evolução do sistema muscular, possibilitando ao cavalo locomover-se eficientemente em altas velocidades ou por longas distâncias, dependendo de sua aptidão física. Em muitos mamíferos o sistema muscular compõe cerca de $40 \%$ a $45 \%$ do peso corpóreo, porém, a de cavalos pode compor até $55 \%$. Somado ao volume muscular, o desempenho atlético dos cavalos é também obtido pelas adaptações musculares frente aos diferentes níveis de esforço, como: o espesso arranjo dos grupos musculares, a arquitetura das suas fibras, a enorme rede vascular e a ultraestrutura altamente especializada ${ }^{1}$.

O exercício induz mudanças reversíveis na ultraestrutura do músculo esquelético dos cavalos, como a elevação da permeabilidade do sarcolema e das proteínas musculares, tais como a mioglobina, creatina quinase $(\mathrm{CK})$ e a aspartato aminotransferase (AST) que são liberadas na circulação ${ }^{2}$. Discretos aumentos dessas enzimas após o exercício não estão associados com a lesão da célula muscular, mas com o aumento da permeabilidade da membrana. Porém, caso haja lesão em nível ultraestrutural durante o exercício, um aumento marcante na concentração dessas proteínas será 
observado, de maneira que, a avaliação da magnitude e do tempo de curso dessas alterações auxilia identificar o tipo da lesão muscular ${ }^{3}$. Em cavalos, essas lesões possuem vários fatores predisponentes, como o aquecimento insuficiente do animal antes da atividade física, as claudicações, o exercício extremo e o treinamento inadequado ${ }^{1}$. Nestes casos, as causas citadas para esse tipo de lesão são o rompimento mecânico, a elevação das concentrações de íon hidrogênio e do lactato nas fibras musculares ${ }^{4}$.

As enzimas comumente utilizadas para indicar a lesão muscular são a AST, CK e a lactato desidrogenase $(\mathrm{LDH})^{5}$. A cinética da elevação sérica e da eliminação de cada uma dessas enzimas é diferente e devem ser consideradas na interpretação dos resultados. A maioria dos cavalos apresenta valores normais das enzimas musculares no momento da lesão e, por isso, podem ser interpretados como animais falsamente negativos para a lesão muscular ${ }^{6}$. O pico de concentração sérica da $\mathrm{CK}$ se dá de 4 a 6 horas após a lesão, e os valores podem voltar ao normal com 24 até 96 horas. A concentração sérica de AST apresenta seu pico após 24 horas, e pode se manter elevada por 5 dias ou até algumas semanas 5 .

Nos casos de elevação da atividade sérica das enzimas CK e AST associada à ausência de sinais físicos de miopatia, não se pode excluir a existência da enfermidade. De forma que, o significado fisiológico da elevação destas enzimas após o exercício, em cavalos clinicamente normais, ainda não está totalmente definido ${ }^{7,8}$.

Anderson ${ }^{8}$ observou que a elevação das enzimas musculares séricas de eqüinos após o exercício foi resultado da mudança na permeabilidade da membrana celular e não de necrose da célula muscular. Volfinger et al. ${ }^{9}$ calcularam a magnitude da lesão muscular em cavalos, baseada na CK liberada do músculo esquelético, e concluíram que somente valores maiores que $10.000 \mathrm{UI} / \mathrm{L}$ da atividade plasmática de CK refletiriam lesão significante.

Segundo Van Der Muelen, Kupers e
Drukker $^{10}$, a elevação da atividade sérica de enzimas musculares superestima possíveis lesões musculares. Todavia, em estudos em humanos, a elevação da atividade sérica das enzimas musculares pós-exercício foi associada com dor e com diminuição da função muscular, e essas evidências podem influenciar o desempenho atlético. Dessa maneira, a determinação da atividade de tais enzimas pode ser útil para o monitoramento da resposta do sistema muscular do cavalo durante o treinamento ${ }^{7,8}$. Neste sentido, os exercícios realizados em esteiras de alta velocidade são capazes de fornecer um modelo para o estudo das atividades séricas das enzimas musculares pós-exercício em cavalos $^{11}$.

Objetivou-se neste trabalho, determinar a atividade sérica das enzimas aspartato aminotransferase (AST), creatina quinase $(\mathrm{CK})$ e lactato desidrogenase $(\mathrm{LDH})$ de cavalos da raça Árabe, antes e até o período de 5 dias após o Teste Padrão de Exercício Progressivo em esteira de alta velocidade.

\section{Material e Método}

Onze eqüinos da raça Árabe, três machos e oito fêmeas, com idades entre 2,5 e cinco anos, pesando $312 \pm 47 \mathrm{~kg}$, foram submetidos a período de condicionamento de quatro semanas, seis dias por semana, uma vez por dia, em protocolo de exercício na esteira (Mustang 2200 - KAGRA, Suíça) e sem inclinação; como: velocidade inicial de $1,8 \mathrm{~m} / \mathrm{s}$ por $5 \mathrm{~min} ; 4,0 \mathrm{~m} / \mathrm{s}$ por $3 \mathrm{~min} ; 6,2$ $\mathrm{m} / \mathrm{s}$ por $2 \mathrm{~min} ; 8,0 \mathrm{~m} / \mathrm{s}$ e $10,0 \mathrm{~m} / \mathrm{s}$ por 1 min cada; $3,0 \mathrm{~m} / \mathrm{s}$ por $2 \mathrm{~min}$ e $1,6 \mathrm{~m} / \mathrm{s}$ por $1 \mathrm{~min}$. Dois dias após o final do período de condicionamento, os animais foram preparados para a realização do Teste Padrão de Exercício Progressivo, por meio da utilização de monitor de freqüência cardíaca (Monitor e transmissor A1 POLAR, Canadá) e do cateterismo da veia jugular, utilizando-se cateter $14 \mathrm{G}$ (Intravenoso periférico - JELCO, Bélgica) acoplado a tubo extensor e torneira de 3 vias, possibilitando coleta de sangue durante 
o exercício, sem a parada da manta da esteira. Com o animal em repouso foi coletada a amostra de sangue venoso (M0). O exercício consistiu da inclinação da esteira a $+6 \%$, velocidade inicial de $1,8 \mathrm{~m} / \mathrm{s}$ por $5 \mathrm{~min}$, a $4,0 \mathrm{~m} / \mathrm{s}$ por $3 \mathrm{~min}$, a $6,0 \mathrm{~m} / \mathrm{s}$ por $2 \mathrm{~min} \mathrm{e}$ fases subseqüentes a $8,0 \mathrm{~m} / \mathrm{s}, 9,0 \mathrm{~m} / \mathrm{s}, 10,0 \mathrm{~m} /$ s e $11,0 \mathrm{~m} / \mathrm{s}$ por 1 minuto cada fase, de modo que a manta da esteira foi parada quando os cavalos não conseguiram acompanhar a velocidade da mesma. Antes (M0) e imediatamente após o término do exercício (M1), e nos momentos pósexercício, 30 minutos (M2), 1 hora (M3), 3 horas (M4), 6 horas (M5), 12 horas (M6), 24 horas (M7), 3 dias (M8) e 5 dias (M9), foram colhidas amostras de sangue venoso para as dosagens das enzimas musculares aspartato aminotransferase (AST), creatina quinase (CK) e lactato desidrogenase (LDH), empregando-se o método colorimétrico utilizando "kits" comerciais (Cia Equipadora de Laboratórios Modernos - CELM, Brasil) e leitura em espectrofotômetro (Cia Equipadora de Laboratórios Modernos CELM, Brasil). Os dados obtidos foram submetidos à análise multivariada de medidas repetidas ${ }^{12}$ visando comparar a cada variável o efeito dos momentos. Para variáveis nas quais não foram verificadas normalidade e/ou igualdade de variâncias, a comparação entre momentos foi feita pelo teste não paramétrico de Friedman ${ }^{13}$. Os valores médios das atividades séricas da AST, CK e LDH foram submetidos à Correlação de Pearson.

\section{Resultados e Discussão}

A atividade sérica da AST no M0 foi de $267 \pm 59,5 \mathrm{UI} / \mathrm{L}$ (Tabela 1). Estes dados estão de acordo com os valores apresentados por Rose e Hodgson ${ }^{14}$ que relataram valores entre 150 a $400 \mathrm{UI} / \mathrm{L}$ e Cardinet III $^{15}$ com valores entre 226 a 366 $\mathrm{U} / \mathrm{L}$. Toledo et al. ${ }^{16}$ observaram valores entre 178,9 a 215,2 UI/L de cavalos em repouso. Menores valores foram referidos por Meyer, Coles e , Coles e Rich ${ }^{17}$ entre 35 e $100 \mathrm{UI} / \mathrm{L}$ e Fernandes ${ }^{18}$ referiu $132,2 \pm$
8,8UI/L em cavalos da raça Árabe antes da prova de enduro. Dos onze animais utilizados, oito foram fêmeas com idade entre 2,5 a 6 anos, o que pode ter influenciado na observação de médias da atividade da AST mais elevadas daquelas citadas por alguns autores. Com relação à idade, Harris et al. ${ }^{19}$ observaram em fêmeas PSI de 2 anos de idade maiores valores da AST que as de 3 anos de idade e Rodrigues et al. ${ }^{20}$ observaram maiores valores de AST em potros de 6 meses a 1 ano de idade. Com relação ao sexo, Harris et al. ${ }^{19}$ relataram maior atividade enzimática em fêmeas comparadas aos machos.

A elevação significativa da atividade sérica da AST observada logo após o término do exercício (Figura 1) foi associada ao processo fisiológico de transferência de fluido do espaço intravascular para o espaço extravascular, observado durante o exercício máximo e, conseqüentemente, resultando em maior concentração dessa enzima por diminuição do volume plasmático, característica essa representada pela diminuição dos valores, ou seja, diluição da enzima do M1 para o M2 e esse com valor semelhante ao M0, sendo essa informação suportada por Rose e Hodgson ${ }^{14}$, que relata que as mudanças no movimento de fluido são de curta duração, havendo retorno para os valores de repouso após 30 minutos do término do exercício.

No M2, M3, M4 e M5 não foram observadas elevações significativas da AST. Resultado este também observado por Fernandes ${ }^{18}$, que citou concentrações semelhantes às de repouso nos momentos referentes aos intervalos 20 a 30 minutos e 80 a 90 minutos pós-exercício. Também Toledo et al. ${ }^{16}$, não verificaram elevação da AST 30 minutos após o término de exercícios de intensidades diferentes. A elevação significativa nos momentos M6 e M7 (Figura 1) definiu o pico de atividade sérica da AST na presente pesquisa e semelhante ao pico relatado por Dunnett et al..$^{21}$ e Muñoz et al..$^{22}$.

Os valores médios da creatina quinase (CK) no M0 foram de $262 \pm 98 \mathrm{UI} / \mathrm{L}$ 
Tabela 1-Médias e desvios-padrão da atividade sérica da aspartato aminotransferase (AST), creatina quinase (CK) e lactato desidrogenase (LDH), em UI/L, dos 11 eqüinos antes e após o Teste Padrão de Exercício Progressivo. Botucatu -São Paulo, Brasil, 2004

\begin{tabular}{lcccccccccc}
\hline & M0 & M1 & M2 & M3 & M4 & M5 & M6 & M7 & M8 & M9 \\
\hline AST & $267,1^{\mathrm{a}}$ & $333,4^{\mathrm{b}}$ & $286,2^{\mathrm{ac}}$ & $279,5^{\mathrm{ac}}$ & $283,5^{\mathrm{ac}}$ & $285,2^{\mathrm{ac}}$ & $289,5^{\mathrm{c}}$ & $291,7^{\mathrm{c}}$ & $283,5^{\mathrm{ac}}$ & $275,5^{\mathrm{ac}}$ \\
(UI/L) & $\pm 59,5^{2}$ & $\pm 72,7$ & $\pm 67,3$ & $\pm 59,6$ & $\pm 67,6$ & $\pm 66,4$ & $\pm 65,7$ & $\pm 65,0^{2}$ & $\pm 58,5$ & $\pm 37,9$ \\
\hline CK & $262,6^{\mathrm{a}}$ & $315,5^{\mathrm{abc}}$ & $275,3^{\mathrm{ab}}$ & $289,4^{\mathrm{bc}}$ & $344,8^{\mathrm{bc}}$ & $362,6^{\mathrm{c}}$ & $322,3^{\mathrm{abc}}$ & $305,7^{\mathrm{abc}}$ & $312,9^{\mathrm{abc}}$ & $261,9^{\mathrm{a}}$ \\
(UI/L) & $\pm 98,0$ & $\pm 118,1$ & $\pm 73,2$ & $\pm 86,2$ & $\pm 109,2$ & $\pm 132,9$ & $\pm 133,1$ & $\pm 89,0$ & $\pm 76,9$ & $\pm 67,7$ \\
\hline LDH & $470,5^{\mathrm{a}}$ & $595,4^{\mathrm{ab}}$ & $515,8^{\mathrm{ab}}$ & $523,1^{\mathrm{ab}}$ & $559,7^{\mathrm{ab}}$ & $513,8^{\mathrm{ab}}$ & $551,6^{\mathrm{ab}}$ & $634,8^{\mathrm{b}}$ & $506,5^{\mathrm{ab}}$ & $518,0^{\mathrm{ab}}$ \\
(UI/L) $\pm 165,8$ & $\pm 206,5$ & $\pm 195,6$ & $\pm 147,5$ & $\pm 193,2$ & $\pm 158,7$ & $\pm 245,9$ & $\pm 270,3$ & $\pm 135,4$ & $\pm 179,7$
\end{tabular}

Valores seguidos de pelo menos uma letra igual não diferem estatisticamente $(\mathrm{p}>0,05)$.

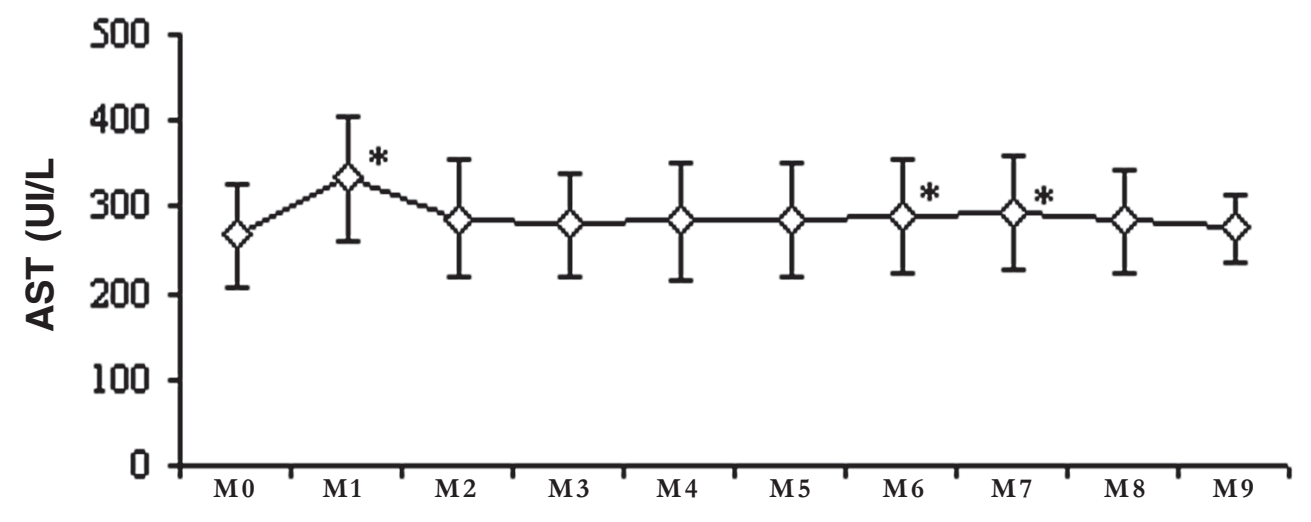

\section{Momento}

Figura 1- Representação gráfica das médias, desvios-padrão e significância da atividade sérica da aspartato aminotransferase (AST) dos 11 eqüinos antes e após o Teste Padrão de Exercício Progressivo. *p $<0,05$

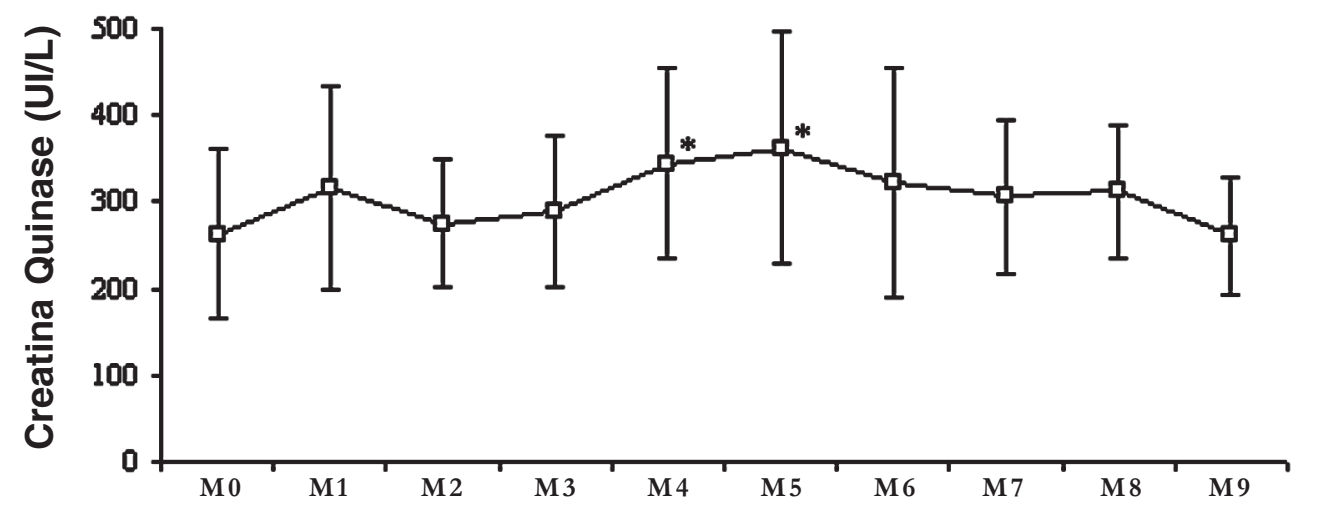

Momento

Figura 2-Representação gráfica das médias, desvios-padrão e significância da atividade sérica da creatina quinase (CK) dos 11 eqüinos antes e após o Teste Padrão de Exercício Progressivo. ${ }^{*} \mathrm{p}<0,05$

(Tabela 1). Estes dados estão de acordo com Rose e Hodgson ${ }^{14}$ que relataram valores entre 100 a 300 UI/L. Menores valores foram referidos por Meyer, Coles e $\operatorname{Rich}^{17}(86 \mathrm{e}$ 140UI/L ) e Fernandes ${ }^{18}$ (84,29 UI/L) nos cavalos Árabes. Já Toledo et al. ${ }^{16}$ observaram valores de 66,5 a 81,3 UI/L. Como observado para a atividade da AST, a variação dos valores de referência de creatina quinase $(\mathrm{CK})$ provavelmente foi decorrente do grupo de animais estudados. Entretanto, Harris et al. ${ }^{19}$ relataram que alguns eqüinos 
podem ter altas atividades enzimáticas fisiológicas da CK, ou que suas enzimas são removidas mais lentamente da circulação, ou, até mesmo, alguns animais apresentariam maior sensibilidade quanto à permeabilidade da membrana da célula muscular frente a estímulo semelhante a outros animais.

Valores da CK semelhantes ao de repouso em M1 e M2 também foram obtidos por Fernandes ${ }^{18}$. Já Toledo et al. ${ }^{16}$ observaram elevação significativa na CK nos exercícios moderados e intensos. A elevação significativa da atividade enzimática no M4 e M5 (Figura 2) corrobora com Valberg, Haggendal e Lindholm ${ }^{5}$ que observou $\mathrm{O}$ pico de atividade 4 a 6 horas após a lesão muscular. Por outro lado, Harris, Marlin e Gray $^{23}$ observaram valores elevados 2 horas após o exercício, enquanto O-Oosterbaan ${ }^{24}$ cita que alterações da CK são mais rápidas que da AST e que os valores de CK elevamse de 6 a 48 horas após a lesão muscular. Valores semelhantes aos de repouso foram observados logo após o pico da CK no M6, M7, M8 e M9. Essa diminuição foi relacionada com a meia-vida plasmática da CK considerada como curta e estipulada por O-Oosterbaan ${ }^{24}$ em torno de 2 horas.

Observou-se valor médio de repouso de LDH de 470,5 \pm 165 UI/L (Tabela 1),
Toledo et al. ${ }^{16}$, na faixa de 167 a 190,9 UI/L para cavalos PSI em repouso. O valor mais elevado pode estar relacionado ao grupo de animais utilizados e suas respectivas características que podem interferir na atividade das enzimas musculares, uma vez que a LDH mensurada refere-se à soma de cinco isoenzimas localizadas no fígado, nos músculos, eritrócitos, células intestinais e tecido renal, sendo que alterações nesses tecidos podem ter influenciado os níveis séricos encontrados. Além disto, concordamos com O-Oosterbaan ${ }^{24}$, que citou que estados não patológicos também podem causar elevações na atividade tanto da AST quanto da LDH, assim como os métodos de coleta das amostras, método de processamento e equipamento utilizado para a determinação da atividade enzimática.

Valores semelhantes da LDH foram observados durante o protocolo de avaliação, à exceção do M7 (Figura 3), considerado como o pico de atividade enzimática. A grande variação das concentrações da LDH após o exercício, também pode ser explicada pela distribuição desta enzima em vários tecidos. Como os valores obtidos se referem à soma das isoenzimas, a interpretação da elevação da $\mathrm{LDH}$ com relação à lesão muscular foi

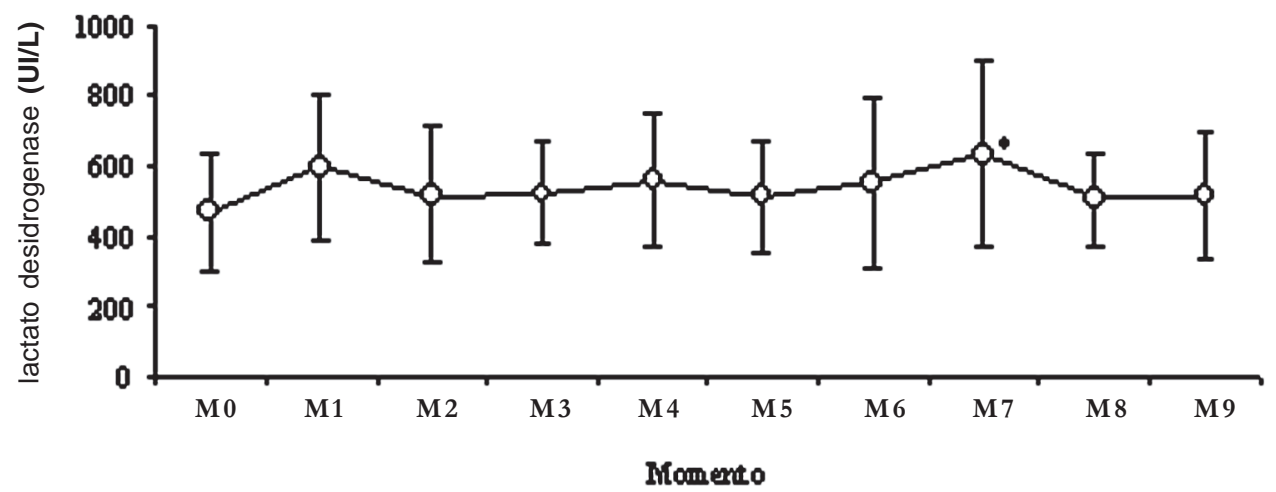

Figura 3- Representação gráfica das médias, desvios-padrão e significância estatística da atividade sérica da lactato desidrogenase (LDH) dos 11 eqüinos antes e após o Teste Padrão de Exercício Progressivo. * $\mathrm{p}<0,05$

diferente do referido por Meyer, Coles e $\operatorname{Rich}^{17}$ (162 e 412UI/L). Já Fernandes ${ }^{18}$, relatou valores entre $321 \pm 31,8 \mathrm{UI} / \mathrm{L}$ nos animais da raça Árabe, enquanto Rose e Hodgson $^{14}$ relataram valor de 250 UI/L. Os menores valores foram observados por comprometida, segundo relatado por Harris $^{25}$.

Avaliando a porcentagem de elevação das atividades enzimáticas com o animal em repouso comparativamente aos picos observados, para AST observaram-se 
elevações de $8 \%$ e $9 \%$, respectivamente para 12 horas $(285 \pm 66,4 \mathrm{UI} / \mathrm{L})$ e 24 horas $(289$ $\pm 66 \mathrm{UI} / \mathrm{L})$, para $\mathrm{CK}$ de $31 \%$ e $38 \%$ respectivamente para 3 horas $(345 \pm 109$ $\mathrm{UI} / \mathrm{L})$ e 6 horas $(363 \pm 133 \mathrm{UI} / \mathrm{L})$ e para $\mathrm{LDH}$ de $35 \%$ no momento referente a 24 horas. Comparando os valores obtidos com os da literatura consultada, observamos grande variação entre os estudos, sendo provavelmente decorrente de fatores que podem influenciar na atividade sérica dessas enzimas, tais como o nível de treinamento do animal, a intensidade e a duração do exercício, bem como o ambiente em que foi realizado o exercício, como citado por Harris $^{25}$. Os diferentes graus de hipóxia e/ ou acidemia muscular desenvolvidos durante o Teste Padrão de Exercício Progressivo influenciaram os valores das concentrações enzimáticas corroborando com os achados de Harris, Marlin e Gray ${ }^{23}$, que observou em animais menos condicionados altas atividades da AST e CK pós-exercício comparativamente a animais com melhor condicionamento físico, e relacionado com o desenvolvimento da hipóxia muscular.

As elevações das atividades enzimáticas encontradas podem ser consideradas de pequena magnitude e predominantemente decorrentes do processo de aumento da permeabilidade da membrana celular e não de sua ruptura. Neste sentido, os valores estão dentro da faixa de normalidade, e, conforme Harris ${ }^{25}$, a porcentagem as atividades da CK e AST séricas não devem elevar-se respectivamente mais de $250 \%$ e $50 \%$ dos valores de repouso, duas horas após um teste de exercício submáximo, seja qual for a aptidão atlética do eqüino.

A maior porcentagem de elevação das enzimas CK e LDH em relação a AST pode ser explicada pela localização das enzimas nas células da musculatura esquelética. Como as enzimas CK e LDH estão presentes no citossol celular, o aumento da permeabilidade da membrana fez com que maior quantidade dessas enzimas fosse transportada para a circulação. Já a concentração sérica da AST foi interpretada levando-se em consideração a sua localização também nas mitocôndrias, e como se considerou a elevação das enzimas decorrente do aumento da permeabilidade da membrana celular, a pequena elevação da AST pode ter sido relacionada com a lesão de pequena magnitude das mitocôndrias. Alterações patológicas estão relacionadas com elevações superiores a $100 \%$ da AST após o exercício, independentemente da intensidade de exercício ou do nível de condicionamento do animal ${ }^{23}$.

Não foram observados quaisquer sinais físicos de miopatia decorrente do protocolo de exercício executado. Contudo, O-Oosterbaan ${ }^{24}$ relatou que em cavalos com atividades de CK maiores que 100.000 UI/ $\mathrm{L}$ não foram observados sinais evidentes de lesão muscular, e muitos cavalos de enduro depois de corridas de $160 \mathrm{~km}$ têm elevações de 5.000 a 30.000 UI/L sem evidências clínicas de doença muscular, não havendo, desta maneira, correlação entre sinais clínicos de lesão muscular e atividade das enzimas musculares.

Observou-se correlação positiva entre a elevação das enzimas, inferindo que as alterações observadas nos momentos correspondentes aos picos de atividade enzimática foram relacionadas com o predomínio das isoenzimas da musculatura esquelética. Contudo, ainda devemos considerar que para avaliação da integridade muscular em resposta ao teste de exercício empregado, que a AST também está presente no fígado e no coração, sendo, portanto, não órgão-específica, como também foi citado por Dunnet et al. ${ }^{21}$. A CK tem uma alta especificidade para a lesão muscular, contudo, está presente também no coração, na musculatura lisa e no cérebro ${ }^{15}$. A atividade da $\mathrm{LDH}$ refere-se à soma de cinco isoenzimas localizadas no fígado, nos músculos, eritrócitos, células intestinais e tecido renal, e elevações da LDH não são específicas, a menos que as concentrações das isoenzimas forem determinadas ${ }^{24}$, de forma que, em futuros estudos se faz necessária a determinação dessas isoenzimas, como no estudo realizado por Michima et al. ${ }^{26}$. 


\section{Conclusões}

As atividades séricas da AST, CK e LDH elevam-se imediatamente e retornam a valores semelhantes ao de repouso 30 minutos após o término do Teste Padrão de Exercício Progressivo. O pico de atividade enzimática da aspartato aminotransferase (AST) foi de 12 horas a 24 horas; da creatina quinase (CK) de 3 horas a 6 horas e da lactato desidrogenase (LDH) 24 horas após o término do Teste Padrão de Exercício Progressivo.

\title{
Serum activities of aspartate aminotransferase, creatine kinase and lactate dehydrogenase in arabian horses submitted to standard incremental exercise test
}

\begin{abstract}
The aim of this study was to determine the serum activities of enzymes aspartate aminotransferase, creatine kinase and lactate dehydrogenase in Arabian horses submitted to exercise on high-speed equine treadmill. Eleven mature Arabian horse were training and submitted to Standard Incremental Exercise Test on high-speed equine treadmill. Venous blood samples were taken before exercise, immediately and $30 \mathrm{~min}$, $60 \mathrm{~min}, 3 \mathrm{~h}, 6 \mathrm{~h}, 24 \mathrm{~h}, 3$ days and 5 days after exercise. The serum activity aspartate aminotransferase, creatine kinase and lactate dehydrogenase were determined. The serum activies of AST, CK and LDH increase immediately and returned to baseline value 30 minutes after exercise. The AST enzyme activity increased at 12 hours and 24 hours, CK at 3 hours and 6 hours, and LDH at 24 hours after Standard Incremental Exercise Test.
\end{abstract}

\section{Referências}

1 SNOW, D. H.; VALBERG, S. J. Muscle Anatomy, Physiology and Adaptations to Exercise and Training. In: HODGSON, D. R.; ROSE, R. J. The athletic horse. Philadelphia: Saunders, 1994. p. 145-179.

2 McCURTCHEN, L. J.; BYRD, S. K.; HODGSON, D. R. Ultrastructural changes in skeletal muscle after fatiguing exercise. Journal Applied Physiology, v. 72, n. 3, p. 1111, 1992.

3 VALBERG, S. J. Muscular Causes of Exercise Intolerance in Horses. The Veterinary Clinics of North America, v. 12, n. 3, p. 495-515, 1996.

4 BREAZILE, J. E. Fisiologia do Músculo Esquelético. In: SWENSON, M. J.; REECE, W. O. Dukes/ Fisiologia dos animais domésticos. 11. ed. Rio de Janeiro: Guanabara, 1996. p. 777-793.

5 VALBERG, S.; HAGGENDAL, J.; LINDHOLM, A. Blood chemistry and skeletal muscle metabolic responses to exercise in horses with recurrent exertional rhabdomyolysis. Equine Veterinary Journal, v. 25, n.1, p. 17-22, 1993.

6 ART, T.; AMORY, H.; LEKEUX, P. Affections
Key words:

Equine. Exercise.

Treadmill. AST. CK. LDH.
Musculaires et Intolerance à l'Effort 1-Pathogénie et Approche Diagnostique. Pratique Vétérinaire Equine, v. 32, p. 59-64, 2002.

7 CARDINET III, G. H.; FOWLER, M. E.; TYLER, W. S. The effect of training, exercise and tying-up on serum transaminase activities in the horse. American Journal Veterinary Research, v. 24, p.980-984, 1963.

8 ANDERSON, M. G. The influence of exercise on serum enzyme levels in the horse. Equine Veterinary Journal, v. 45, n. 4, p. 361-370, 1975.

9 VOLFINGER, L. et al. Kinetic evaluation of muscle damage during exercise by calculation of amount of creatine kinase released. American Journal of Physiology, v. 266, R. 434-341, 1994.

10 VAN DER MEULEN, J. H.; KUPERS, H.; DRUKKER, J. relationship between exercise-induced muscle damage and enzyme release in rats. Journal Applied of Physiology, v. 71, n. 3, p. 999-1004, 1991.

11 SICILIANO, P. D. et al. Effect of conditioning and exercise type on serum creatine kinase and aspartate aminotransferase activity. Equine Veterinary Journal, v. 18, p. 243-247, 1995. Supplement.

12 MORRISON, D. F. Multivariate statistical methods. Mc Graw Hill: São Paulo. 1990. 450 p. 
13 ZAR, J. H. Biostatistical analysis. New Jersey: Prentice-Hall, 1996. p. 718.

14 ROSE, R. J.; HODGSON, D. R. An overview of performance and sport medicine. In: HODGSON, D. R.; ROSE, R. J. The athletic horse. Philadelphia: W. B. Saunders, 1994. p. 5-11

15 CARDINET III, G. H. Skeletal Muscle Function. In: KANEKO, J. J.; HARVEY, J. W.; BRUSS, M. L. Clinical biochemistry of domestic animals. San Diego: Academic Press, 1997. p. 426-429.

16 TOLEDO, P. S. et al. Atividade sérica de aspartato aminotransferase, creatina quinase, gamaglutamiltransferase, lactato desidrogenase e glicemia de cavalos da raça P.S.I. submetidos a exercícios de diferentes intensidades. Revista Brasileira de Ciência Veterinária, v. 8, n. 2, p. 73-77, 2001.

17 MEYER, D. J.; COLES, E. H.; RICH, L. J. Exames Laboratoriais e Enzimologia Clínica. In: Medicina de laboratório veterinária. São Paulo: Roca, 1995. p. 9.

18 FERNANDES, W. R. Alterações dos Parâmetros do Eletrocardiograma e da Crase Sanguínea em Eqüinos das Raças Árabe e Mangalarga, bem como Mestiços, submetidos à Prova de Enduro. 1994. 73 f. Tese (Doutorado)- Faculdade de Medicina Veterinária e Zootecnia, Universidade de São Paulo, São Paulo, 1994.

19 HARRIS, P. A. et al. Some factors influencing plasma AST/CK activities in Thoroughbred racehorses. Equine Veterinary Journal, v. 9, p. 66-71, 1990.

20 RODRIGUES, M. S. N. et al. Avaliação de alguns constituintes bioquímicos séricos em eqüinos sadios, da raça Mangalarga Paulista, criados no estado de São Paulo. In: CONGRESSO PAULISTA DE MEDICINA VETERINÁRIA, 6., 2004, São Paulo. Anais... São Paulo: CONPAVET, 2004. p. 57.

21DUNNETT, M. et al. Plasma carnosine concentration: diurnal variation and effects of age, exercise and muscle damage. Equine Exercise Physiology 6. Equine Veterinary Journal, p. 283-287, 2002. Supplement 34.

$22 \mathrm{MUN \tilde {OZ }}$, A. et al. Effect of training duration and exercise on blood-borne substrates, plasma lactate and enzymes concentrations in Andalusian, Anglo-Arabian and Arabian breeds. Equine Veterinary Journal, v. 34, p. 245-251, 2002. Supplement.

23 HARRIS, P. A.; MARLIN, D. J.; GRAY, J. Plasma aspartate aminotransferase and creatine kinase activities in thoroughbred racehorses in relation to age, sex, exercise and training. The Veterinary Journal, v. 155 n. 3, p. 295-304, 1998.

24 O-OOSTERBAAN, S. V. Appropriate blood variables helpful in diagnosing (sub)clinical disease in the horse. In: LINDNER,A. Conference on Equine Sports Medicine and Science - Cordoba - Spain. Wageningen Pers: Wageningen, 1998. p. 14-33.

25 HARRIS, P. A. Enfermidade Musculoesquelética. In: REED, S. M.; BAYLY, W. M. Medicina interna eqüina. Rio de Janeiro: Guanabara, 2000. p. 327-329.

26 MICHIMA, L. E. S. et al. Estudo das alterações de creatina quinase total e sua isoenzima CKMB determinadas por exercício físico de alta intensidade em cavalos de enduro. In: VI CONGRESSO PAULISTA DE MEDICINA VETERINÁRIA, 6., 2004, São Paulo. Anais... São Paulo: CONPAVET, 2004. p. 54 